\title{
Parejas mixtas e hibridación transcultural en España. Reflexiones sobre un nuevo fenómeno desde perspectivas comparativas a nivel europeo
}

\section{Gerhard Steingress}

Universidad de Sevilla. Departamento de Sociología gst@us.es

\section{Resumen}

A lo largo de las últimas décadas, la mayoría de las sociedades europeas se han transformado en multiculturales, debido a la inmigración laboral y al surgimiento de nuevos estilos de vida vinculados a la intensificación de la comunicación intercultural y a la movilidad geográfica, como consecuencia de las tecnologías globalizadoras. Este proceso ha dado como resultado no sólo los conflictos sociales entre poblaciones culturalmente divididas, sino también el diálogo y la hibridación transcultural. El artículo intenta abrir paso hacia el estudio más exhaustivo de este fenómeno, introduciendo en la temática unas reflexiones sobre la dimensión estructural-objetiva del fenómeno para preparar futuras investigaciones de carácter cualitativo sobre la dimensión interactivo-subjetiva. Basándose en datos estadísticos, el artículo analiza el aumento significativo de las parejas mixtas en España y en Andalucía durante las dos últimas décadas desde una perspectiva comparativa, poniéndose en relación los procesos migratorios. En el trabajo, se consideran las parejas binacionales o biculturales como un fenómeno novedoso y un hecho social que induce a la redefinición de los estándares culturales que incluyen conflictos como la segregación, al mismo tiempo que se apunta la posibilidad de establecer comunicación intercultural e hibridación como requisitos de una necesaria reconstitución cultural de las sociedades avanzadas.

Palabras clave: migraciones; estilos de vida; Andalucía.

Abstract. Mixed couples and transcultural hybridisation in Spain. Considering a new phenomenon from a comparative perspective on a european level

During the last few decades, most European societies have become multicultural due to the increase in labour immigration and the rise of new life-styles related to the intensification of intercultural communication and geographical mobility as a result of globalising technology. This process has contributed not only to social conflicts between culturally divided populations but also to dialogue and transcultural hybridization. The article attempts to open the path toward further, more comprehensive studies of this phenomenon, focussing the subject with the help of some reflections on its structural and objective dimension in 
order to prepare future qualitative analysis of the subjective dimension of social interaction. Based on statistical data, this article analyzes the significant rise in the number of mixed couples in Spain and Andalusia during the last two decades from a comparative perspective and related with the migration processes. It considers binational or bicultural couples as a new phenomenon and a social fact that induces the redefinition of cultural standards including conflicts and segregation, but also the chance for intercultural communication and hybridisation as the prerequisites for a necessary cultural reconstitution of advanced societies.

Key words: migrations; life-styles; Andalusia.

\section{Sumario}

1. Prólogo 4. Los casos de España y Andalucía

2. Objetivos, marco teórico

5. Conclusiones

y metodológico

Referencias bibliográficas

3. El auge de los matrimonios mixtos en varios países europeos

\section{Prólogo}

A lo largo de la historia de la humanidad, los hombres y las mujeres nunca se han resistido a buscar pareja fuera de su propio grupo social y cultural. Los motivos son varios, pero siempre están vinculados a necesidades tanto personales como sociales y culturales. Como demuestran algunos ejemplos mitológicos, la formación de este tipo de parejas no siempre estuvo guiada por el amor o la seducción, sino que también se impuso por necesidad y con violencia.

Incluso los dioses actuaron así. El propio Zeus, por ejemplo, transformándose en seductor toro blanco, símbolo de la virilidad y del poder en las culturas de la región de Mesopotamia, secuestró a Europa, la hija del rey fenicio Agenor ${ }^{1}$.

En el caso de otro ejemplo de rapto, el de las sabinas, predominan la violencia y la sumisión de la mujer por parte de los hombres necesitados. Según el mito, Rómulo, uno de los principales fundadores de Roma, organizó unos juegos competitivos a los que invitó a los habitantes de las ciudades vecinas. Los de la población de la vecina Sabinia acudieron al evento junto con sus mujeres e hijos. Los romanos, a los que faltaban mujeres, las raptaron para convertirlas en sus esposas y, de esta manera, solucionar un problema demográfico.

En ambos casos, se reflejan motivos que marcan toda la historia de las relaciones de parejas con participación extranjera hasta hoy en día. Los contactos interculturales favorecieron el establecimiento de relaciones matrimoniales por muy distintos motivos a modo de intercambio. Es decir, los intereses económico-políticos condujeron a los poderosos de grandes y pequeños imperios

1. Heródoto es menos ambicioso y cuenta que fueron los minoicos que la raptaron y se la llevaron a Creta. 

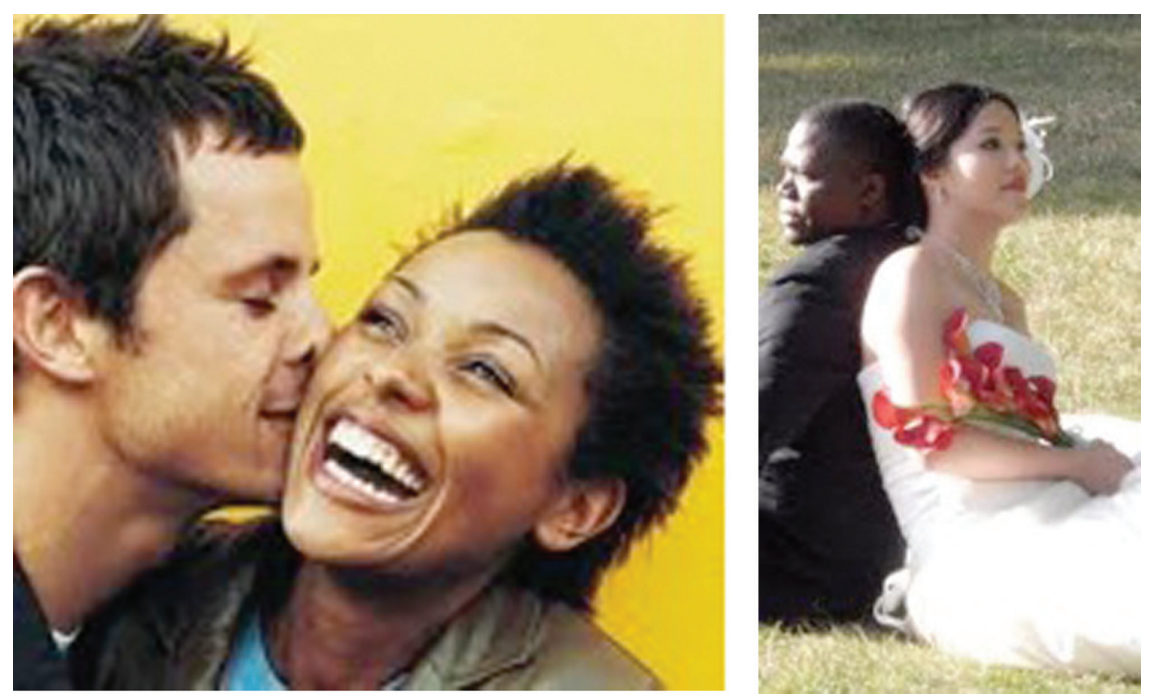

a reforzar su posición dinástica mediante una política de matrimonio; y las necesidades y las posibilidades surgidas a partir de los mercados matrimoniales incitaron el cambio de comportamiento de muchos a la hora de elegir su pareja.

Aparte de lo meramente político y económico, existió, pues, una dimensión cultural que influyó en el desarrollo histórico de los pueblos, con lo cual se demostró el carácter dinámico y abierto de las culturas. Hasta aquí la historia, pero, en la Europa actual, este fenómeno ha vuelto a llamar la atención. Desde el punto de vista cuantitativo, dicho fenómeno está cada vez más presente e influye en los procesos demográficos. No obstante, desde la perspectiva cualitativa, requiere una explicación como elemento importante del proceso de globalización o mundialización al que están sometidas las sociedades y las culturas en el planeta.

\section{Objetivos, marco teórico y metodológico}

El presente artículo inicia, en primer lugar, unas investigaciones novedosas y, por ello, predomina en él el carácter todavía heurístico e hipotético de los planteamientos teóricos y metodológicos presentados. En segundo lugar, se apoya en datos estadísticos y en los conocimientos relacionados con el objeto principal, que son las parejas mixtas ${ }^{2}$. Finalmente, el estudio llama la atención

2. Aunque todas las parejas conyugales son configuraciones sociales de elementos (personas y personalidades) cuya diversidad produce formas de mestizaje (mixity), entendemos como "parejas mixtas» especialmente tanto a los matrimonios heterosexuales oficiales como a los de hecho, formados por personas con un trasfondo étnico-cultural significativamente diferente. El grado de «significancia» de esta diferencia va más allá de la dimensión psicológica de la personalidad y se mide, sobre todo, a partir de la constitución étnica de los componentes 
sobre el aumento significativo de este tipo de formación interpersonal en la mayoría de los países de la Unión Europea y aporta datos referentes a España y a una de sus regiones, Andalucía. Esta selección, a nivel comparativo, se justifica con el valor cognitivo que ofrece el recurso a la diferencia social y cultural de las regiones implicadas. Mientras que, a nivel europeo, la mayoría de los países cuentan desde hace medio siglo con un creciente nivel de multiculturalidad, en España este hecho aparece con carácter masivo sólo a lo largo de las últimas dos décadas. Por su parte, Andalucía cuenta con un estatus peculiar, debido a que se trata de una comunidad preferentemente de tránsito para los inmigrantes, al mismo tiempo que un lugar de residencia para muchos extranjeros.

A primera vista, acercarse al fenómeno de las parejas mixtas significa tener en consideración dos procesos sociales importantes en la sociedad actual: primero, la inmigración y, segundo, el cambio estructural de la familia como institución social nuclear. No obstante, aquí interesa lo que está detrás de esta dinámica: el cambio cultural relacionado con estos procesos. Es decir, el cambio estructural de la familia es considerado un efecto, entre otros, de la inmigración. Al mismo tiempo, los inmigrantes y las inmigrantes encuentran en la familia una puerta de entrada en una cultura y en un sistema social ajeno al suyo. Este fenómeno de cohabitación para la cohesión social se da, curiosamente, en una situación donde se habla frecuentemente de la «disolución de la familia» (Sotelo, 2006) y la aparición de nuevas formas de convivencia como pareja que se ajustan más a las exigencias del entorno laboral, social y cultural actual. Por supuesto, la "disolución de la familia» es, sobre todo, la disolución de un tipo anticuado de familia, y las parejas mixtas entran en juego en este sentido, lo cual cambia el paisaje cultural (y educativo) de los países con presencia significativa de inmigrantes y sus descendientes. Aunque, a primera vista, parece que los procesos migratorios son un factor decisivo en este sentido, habrá que tener en cuenta más aspectos, tanto vinculantes como independientes de ellos. Por esta razón, se enfocarán algunas de sus consecuencias para el cambio social y cultural en el marco de la llamada «sociedad avanzada» ${ }^{3}$ en

de la pareja, como consecuencia de los distintos modos de enculturación en el país de procedencia o el entorno étnico-social relativamente cerrado al que pertenecen en el país de acogida (lengua, religión, hábitos y costumbres). Comprendemos esta ambigüedad como consecuencia del carácter dialéctico de las relaciones socioculturales en la era de la globalización: las parejas mixtas manifiestan tanto las diferencias culturales como su superación, la heterogeneidad en situaciones de homogeneidad.

3. En la sociología actual, este término todavía se usa de manera muy opaca, aunque su tendencia apunta a un modelo social basado en una combinación de los parámetros de la sociedad postindustrial (D. Bell) — surgidos a partir de la revolución científico-técnica; el aumento del conocimiento como factor estratégico, tanto de la producción como de la organización social, y el cambio correspondiente en el sistema ocupacional (aumento del sector terciario) - y la correspondiente ética de la postmodernidad, que se ha convertido en el metadiscurso de la sociedad postindustrial que refleja y justifica los cambios sociales, técnicos y económicos a nivel cultural. Entendemos, pues, como sociedades avanzadas aquellas sociedades básicamente modernas que son capaces de reducir la asintonía cultural producida por los avances tecnológicos, económicos y sociales para responder de manera relativamente creativa a los nuevos retos. 
cuanto tipo de sociedad cuya heterogeneidad ha aumentado debido a una serie de nuevos parámetros, entre los cuales destacan la composición étnicocultural de la población y la hibridación cultural como consecuencias de la intensificación de los procesos interculturales, facilitados sobre todo por las nuevas tecnologías de la comunicación.

Respecto a esto, habría que subrayar que, en la historia de la sociología, se han analizado (y se siguen estudiando) con intensidad los procesos migratorios. El célebre trabajo empírico de William Thomas y Florian Znaniecki sobre los campesinos polacos en Europa y América, publicado entre 1918 y 1920 (versión española de 2004), abrió el camino al análisis sociocultural y a la dinámica del cambio en el marco de la inmigración en otra esfera cultural. Dichos autores demostraron como cambiaron las personas como consecuencia del paso de una cultura a otra. Además, en esta misma línea, sus contemporáneos Abram Kardiner y Ralph Linton profundizaron en la influencia del medio cultural concreto («nacional») sobre la constitución de la personalidad, destacando las diferencias interculturales como factores objetivos que acuñan la personalidad modal. Por su parte, Talcott Parsons, desde la perspectiva estructural-funcionalista, destacó el papel de la cultura como conjunto de pautas, valores y normas que aportan al sistema social estabilidad, cohesión y continuidad.

No sorprende que, en el caso de Estados Unidos, esta temática fuera tratada sobre todo desde la perspectiva de las relaciones entre las razas como elemento crucial de la estructuración social y de las diferencias culturales. En 1941, Robert K. Merton publicó un artículo sobre los matrimonios interraciales (Merton, 1941), donde hizo referencia a su carácter ambiguo. En él destacó cómo, mediante este tipo de relaciones, se redefine el estatus social a partir de un intercambio de posibilidades y perspectivas, además, se reduce el potencial de conflictividad entre los grupos de procedencia involucrados, de modo que estos matrimonios influyeron en la cohesión social, a pesar de los múltiples obstáculos que el entorno social mayoritario les imponía. Desde entonces, las tasas de matrimonios mixtos son considerados indicadores de la distancia entre los grupos sociales y sus sujetos, los propios matrimonios mixtos, como agentes que producen cohesión social ${ }^{4}$.

No obstante, todos estos teóricos comprendieron la cultura como un sistema en el marco de un tipo de sociedad constituida como nación, es decir, como una asociación basada en la integración social mediante la asimilación de los «extranjeros» (sea la aculturación de los recién llegados o la enculturación de sus

4. Raza, religión y etnia suelen ser los factores considerados como decisivos para explicar la dinámica en la elección de los cónyuges (Gordon, 1964). Otros autores destacan el cese de la religión como principal factor en la configuración de los matrimonios mixtos. Gordon Matthijs Kalmijn (1991), en un estudio longitudinal más reciente sobre matrimonios mixtos en Estados Unidos, ha demostrado que, desde 1920, han cambiado significativamente los criterios de selección de los cónyuges y que el factor «educación» ha reemplazado al anterior de la religión. Es decir, el cambio cultural de la sociedad varía los criterios de selección marital, lo que parece un hecho importante para explicar la dinámica actual de las parejas mixtas en la sociedad avanzada y postmoderna. 
descendientes). Hoy día, identificar la integración social de los inmigrantes con su asimilación causaría más problemas que soluciones. La multiculturalidad requiere una dinámica social y cultural que vaya más allá de una integración mediante asimilación: requiere reconocer el papel y la importancia de los procesos de hibridación transcultural. Esta semántica sociológica, surgida durante la segunda mitad del siglo pasado, a partir del cambio paradigmático liderado por el discurso del deconstructivismo y los teóricos del postcolonialismo, iniciado por Edward Said (1978) y Homi Bhabha (1994), ha cambiado profundamente el peso de los elementos del intercambio cultural al que se refirió Merton. Así, de la homogeneidad cultural, la asimilación y la aculturación mediante el intercambio interesado se pasó a la multiculturalidad y a la hibridación como las principales características de la sociedad avanzada.

Por esta razón, y a pesar de las dificultades de organización de la multiculturalidad en términos de igualdad, el rechazo o la resistencia a los grandes contingentes de inmigrantes que habitan en las sociedades de acogida y la exigencia de su asimilación a lo que se considera los estándares culturales del país se ven confrontados con una cada vez más notable actitud tolerante hacia la heterogeneidad y el mestizaje cultural. No obstante, una cosa es la tolerancia hacia los otros y su cultura, y otra cosa es la disposición a asimilarse mutuamente desde las culturas involucradas (hibridación transcultural).

En cualquier caso, las reacciones son también, se puede suponer, un efecto del aumento de la visibilidad de las parejas mixtas en las sociedades tradicionalmente monoculturales. Por esta razón, la sociología contemporánea ${ }^{5}$ se ve obligada a repensar algunos de sus conceptos (cultura, interculturalidad, multiculturalidad, aculturación, enculturación, asimilación, etc.), para poder explicar la nueva dinámica de las relaciones sociales constituyentes de la sociedad, las cuales se negocian desde perspectivas culturales diferentes (Steingress, 2002) ${ }^{6}$. El carácter culturalmente heterogéneo del tipo de sociedad avanzada, tal como se refleja en el concepto de la postmodernidad, abarca tanto el eclecticismo cultural como la hibridación transcultural como nueva fórmula de creación cultural ${ }^{7}$. Es

5. El término «etnocentrismo» fue creado como concepto sociológico por William Summer en 1906. La sociología es una ciencia que estudia el etnocentrismo, pero, como ciencia que estudia la realidad social históricamente concreta, es una conceptualización de esta realidad, su reflejo semántico. Pensar las categorías sociales a nivel de la sociedad moderna constituida en el marco del estado nacional significa explicarla a base de una semántica de lo nacional. Consecuentemente, el deconstructivismo en la teoría social (compartida por la antropología social-cultural y la sociología) ha criticado, a lo largo de las últimas décadas, esta tendencia etnocentrista de la sociología.

6. Aun más. Teniendo en cuenta Georg Simmel y su concepto de sociabilización, habría que reformular las relaciones intersubjetivas para responder, una vez más, a la pregunta de qué es lo que hace posible la sociedad bajo las condiciones de la modernidad avanzada.

7. Las aportaciones más significativas en este sentido fueron las de Homi Bhabha (1994) y Néstor García Canclini (2001), defendidas desde la postura del postcolonialismo en la teoría social. Por otro lado, más actualmente, el estudio de los espacios híbridos se ha convertido en tema central de los estudios culturales y cuenta con aportaciones importantes (Becker y McCall, 1990; Hannerz, 1992; Geertz, 2000; Featherstone y Lash, 1999; entre otros más). 
decir, las sociedades contemporáneas cuentan con un creciente «espacio híbrido» donde la alteridad impone pautas nuevas que disuelven las anteriormente defendidas «culturas nacionales» y hacen surgir la transculturalidad como nuevo modo de ser y de pensar (Welsch, 1999).

Llegados a este punto, parece justificado hacer una observación clave: aunque se han estudiado en profundidad los fenómenos migratorios y del cambio cultural en la era postmoderna, el tema de las parejas mixtas sigue al margen de la investigación sociológica, sobre todo si se refiere a España, donde, por el momento, sólo destacan los trabajos de Evangelina Rodríguez Marcos (2006), Antonio Alaminos Chica (2008a, 2008b), Marcos Alonso Bote Díaz (2004), así como Clara Cortina et al. (2007). Este hecho no sorprende si tenemos en cuenta que - a diferencia de otros países con una más larga tradición de interculturalidad - se trata de un fenómeno cuya visibilidad ha aumentado sólo a lo largo de las últimas dos décadas ${ }^{8}$.

Aparte de estas contribuciones, el tema de la multiculturalidad y de la interculturalidad que forma el trasfondo sociológico de las parejas mixtas, existen otras que se acercan a esta temática desde la perspectiva de la familia como institución y los cambios a que está sometida, tanto en su configuración interna como en su relación externa. En su Manual de sociología de la familia (2003), Pierpaolo Donati subraya que la sociología suele contemplar a la familia desde el exterior, es decir, con una mirada funcionalista, mientras que "pocos textos intentan interpretar el fenómeno familia "desde dentro" de lo que sociológicamente significa y expresa» para concretizar su perspectiva, que consiste en analizar "qué significa hacer familia» (Donati, 2003: 11). No obstante, tanto en el libro de Donati como también en el coordinado por Dionisio Borobio, titulado Familia e interculturalidad (Borobio, 2003), el fenómeno es tratado exclusivamente a nivel de la situación y las consecuencias de la integración de familias de inmigrantes en la sociedad multiétnica. La «mezcla cultural» se produce, pues, no en el seno de familias o de parejas compuestas por individuos con diferente trasfondo cultural o étnico, sino a nivel de familias de foráneos, «familias de origen extranjero» o «vinculadas a la inmigración» (Giménez, 2003: 135) y el entorno social de la sociedad de acogida. Encontramos esta perspectiva también en Donati: «La llegada de personas y de familias ligadas a modelos culturales diferentes de las culturas autóctonas no plantea sólo problemas de relación con otras culturas, la interacción con ellas, sino también de acogida e inserción social» (Donati, 2003: 366). Giménez, por su parte, insiste en afirmar que "la coexistencia de diversas culturas en un mismo lugar y tiempo o multiculturalismo no soluciona, sin embargo, el problema de la relación con el otro diferente» y concluye que: «la inmigración ha revelado el déficit

8. Es significativo que, en el libro de Martine Segalen, publicado por primera vez en 1981 y una de las contribuciones más importantes al tema del desarrollo histórico de la familia, todavía no se encuentre ninguna referencia a las familias interculturales (Segalen, 2004). Tampoco encontramos información al respecto en el extenso estudio sobre la inmigración musulmana en Europa, publicado en 2004 por Víctor Pérez-Díaz, Berta Álvarez Miranda y Elisa Chuliá. 
no resuelto de la multiculturalidad» (Giménez, 2003: 33). Con esto queda demostrada la estrecha relación entre la inmigración, la multiculturalidad ${ }^{9}$ y el aumento de las parejas mixtas, así como sus consecuencias, el lugar donde ocurren y el hecho de ser generadoras del cambio cultural en las sociedades avanzadas. Pero este proceso no sólo se percibe como conflictivo, sino que, además, delata la laguna de conocimiento sobre este proceso. Así lo expresa Donati, y su conclusión va en la misma dirección del presente artículo: «Las familias emigrantes se aproximan a la cultura moderna en muchos aspectos, pero en otros la rechazan. No se sabe bien si y cómo la asimilarán, y qué producto cultural se derivará» (ibídem: 367; la cursiva es nuestra).

Ahora bien, en nuestro contexto temático, las parejas biculturales no se analizan en el marco específico de la sociología de la familia. Nuestra perspectiva es aún más microscópica y enfoca los procesos interactivos y simbólicos entre los componentes que forman una pareja mixta. El objetivo final del proyecto consiste más bien en explicar que la asimilación innovadora en situaciones de multiculturalidad se desarrolló necesariamente a través de la hibridación transcultural ${ }^{10}$. De acuerdo con esta hipótesis, se intenta explicar:

a) Cómo se desarrolla la asimilación cultural mutuamente en el seno de una pareja (sea familia o no) con trasfondo cultural-étnico-religioso diferente.

b) Cómo se construyen los nuevos productos culturales «derivados» mediante la interacción a nivel de la pareja y en relación con su entorno social.

c) Qué impacto tienen estos nuevos productos culturales derivados en la sociedad de acogida y el cambio cultural a la que está sometida bajo las influencias de la globalización.

En fin, se trata de aplicar la metodología que Donati denominó «desde dentro" y destacar la producción cultural como hibridación transcultural a nivel de la negociación de nuevas identificaciones en el espacio social que representa una pareja mixta. Orientándose en esta línea del constructivismo simbólico, se plantea la temática de la siguiente manera: ¿De qué modo las parejas mixtas actúan como sujetos de negociación cultural ubicados en los espacios híbridos en el marco de la sociedad multicultural y cuáles son sus efectos sobre las culturas involucradas? No obstante, para precisar el análisis,

9. Así lo ve también Salustiano del Campo refiriéndose al espectacular aumento del número de inmigrantes durante la década de 1990: «Estos datos indican con mucha claridad que el multiculturalismo que actualmente existe en España es producto de la inmigración» (Campo, 2003: 204).

10. Las debilidades del multiculturalismo son bien conocidas (Welsch, 1999). Por esto, Salustiano del Campo (2003: 203-207, aquí: 205) opta por un pluralismo «bajo el cual pueden convivir distintas culturas dentro de un marco común basado en los derechos de los individuos» y que permite la integración social de los inmigrantes mediante un intercambio cultural consensuado y de acuerdo con los principios de convivencia guiado por los valores democráticos y los derechos humanos. De acuerdo con esta idea, consideramos la hibridación transcultural como un proceso interactivo de construcción de una nueva cultura que asimila todo lo que se corresponde a los valores del humanismo y la pluralidad. 
habrá que empezar con el primer paso: concretizar y analizar las parejas biculturales a nivel socioestructural, utilizando los datos estadísticos existentes para demostrar que se trata de un fenómeno sociocultural que adquiere cada vez más importancia en las sociedades multiculturales.

En este sentido, el programa de investigación, iniciado por el grupo de investigación internacional sobre parejas mixtas (MIXCOUP) ${ }^{11}$, exige una combinación de datos que abarca tanto el análisis estructural (macrosociológico), como el análisis de los procesos interactivos (microsociológicos), en el sentido del paradigma integral propuesto y argumentado por Ritzer (1995: 453-613).

De acuerdo con este presupuesto estratégico, el análisis de la dinámica social y cultural, tal como se refleja en el aumento de las parejas mixtas, está conforme con los objetivos del análisis sociológico, tal como lo resume Haller: «El objetivo del análisis estructural consiste en describir detalladamente una sociedad según sus características (parámetros) y su distribución, con el objeto de explicar el comportamiento de las personas (y sobre todo sus pautas de interacción) a partir de ellas» (Haller, 1999: 189; mi traducción). Es decir, y de acuerdo con las teorías de Merton (y Weber), según las cuales las categorías sociales son agregados de individuos con trasfondo normativo distinto que se relacionan en situaciones sociales concretas, la interacción social como punto de referencia del análisis social incluye una interpretación de la situación que influye en las relaciones sociales. No obstante, dicha interpretación está, a pesar de su carácter subjetivo, anclada en la realidad social y cultural como marco referencial objetivo. Las identidades son, pues, consecuencias dinámicas de identificaciones circunstanciales con objetos ajenos a la conciencia subjetiva, socialmente y culturalmente construidas que se convierten en puntos de referencia para la acción social individual.

La importancia de las parejas mixtas como agentes de la comunicación intercultural ha sido reconocida por parte de la sociología de la inmigración. Así, en la introducción de una aportación a un libro dedicado al tema de la migración y la integración, leemos: «La elección de una pareja procedente de la sociedad de acogida es considerado uno de los indicadores más fiables de la integración de los inmigrantes y sus descendientes [...] Los matrimonios interétnicos significan interacciones duraderas más allá de los límites de los grupos étnicos y refuerzan así la integración en muchos otros ámbitos de la vida [...] La cuestión, si se puede percibir una tendencia hacia el intermarriage como una de las formas centrales de la asimilación social, y qué mecanismos la refuerzan o la obstaculizan, es, pues, de importancia fundamental en cualquier contexto

11. Sus miembros son los autores de este monográfico. Entendemos como parejas mixtas tanto los matrimonios oficiales como los de hecho formados por personas con un trasfondo étnico-cultural significativamente diferente. El grado de «significancia» de esta diferencia se mide, sobre todo, a partir de la constitución étnica de la personalidad de los componentes de la pareja, como consecuencia de su enculturación en el país de procedencia o el entorno étnico-social relativamente cerrado al que pertenecen en el país de acogida (lengua, religión, hábitos y costumbres). 
de migración e integración» (Schroedter y Kalter, 2008: 351; traducción mía). De acuerdo con esta afirmación, parece claro que se trata de ir más allá de la mera comprensión de las parejas mixtas como fenómeno relacionado con la inmigración en Europa. Más bien se trata de analizar los efectos culturales que su presencia, cada vez más frecuente, tiene sobre las bases culturales de las sociedades afectadas.

Las consecuencias metodológicas extraídas de este presupuesto teórico formulado por el constructivismo simbólico son evidentes: se trata de explicar el aumento del número de parejas mixtas (aspecto demográfico) a partir de la intensificación de los procesos migratorios en un sentido amplio (aspecto objetivo-estructural), como trasfondo para el cambio en el comportamiento marital (aspecto subjetivo-interactivo). Retomando el concepto del paradigma sociológico integral de Ritzer, nos parece muy acertado lo que escribe Max Haller respecto a las situaciones de heterogeneidad multiforme aplicadas al análisis de la sociedad avanzada: «la existencia de múltiples parámetros estructurales diferentes y la poca intercorrelación de estos parámetros aumenta la probabilidad de una interacción transgrupal. La razón de ello está en que cada grupo es relativamente pequeño, de modo que sus miembros se ven obligados a establecer relaciones con los de otros grupos en una serie de esferas de la vida» (ibídem). De acuerdo con esto, entendemos las parejas mixtas como agentes sociales que negocian nuevos proyectos de identificación cultural a nivel miscrosociológico dentro del marco de lo que Schütz, Berger, Luckmann y Habermas denominan el «mundo de la vida». Es decir, proyectos que, formulados como hipótesis, pueden influir en el cambio cultural, sobre todo en el de los valores, las normas sociales y las costumbres de una población que cada vez es, étnica y culturalmente, más heterogénea. Lo que ocurre a nivel interpersonal no es simplemente la consecuencia de las estructuras y de los aspectos normativos de la sociedad, sino que, al mismo tiempo que los representa, los interpreta y los cambia. Lo estructural y lo interactivo son, pues, dos dimensiones del mismo proceso social y cultural. Para comprender esta constelación teórico-metodológica, hay que recordar lo que en sociología se denomina "método genético", en relación con los procesos constitutivos de sociedad. En este sentido, fue Georg Simmel (1923) quizás el primer sociólogo que destacó la génesis de la sociabilidad a partir de la intervención de un "tercero» constituyente. De acuerdo con su teoría de la alteridad, un grupo social formado por dos personas no existe: sólo la presencia de un tercero (o un tercer elemento presente en la conciencia de la pareja) constituye un grupo social. De este modo, tal como subraya Bedorf (2010: 131), estamos ante una «intersubjetividad asimétrica», que "significa que la libertad no es la libertad de un sujeto autónomo, sino el espacio creativo que se abre al inventar las respuestas a las exigencias del Otro». De manera parecida, el concepto de «acción social», de Max Weber, también ahonda en ello, al definirlo como acción dirigida hacia otros, pero guiado por un sentido subjetivo que sólo adquiere significado social si es conocido, compartido o rechazado por el otro. 
Ahora bien, siguiendo nuestra hipótesis principal, esta «intersubjetividad asimétrica» es un concepto que responde a la exigencia formulada por Haller, que coincide con las posturas de la sociología constructivista y comprensiva, así como con la propuesta de Ritzer de un paradigma sociológico integrado. Apoyándonos en lo dicho por Schroedter y Kalter, las parejas mixtas serían un ejemplo de este tipo de constelación social a partir de la diferencia cultural que exige un esfuerzo (y unas condiciones fuera de la norma) para solucionar una serie de problemas sociales y culturales relacionados con la integración y la cohesión social en las sociedades multiculturales. Es la diferencia cultural la que incita un nuevo tipo de comunicación transcultural cuyo efecto consiste en acercar lo que comúnmente se malinterpreta como «identidad cultural» a la realidad social cambiante.

Falta añadir otro concepto para redondear las bases teóricas de este artículo: mientras que, hasta el momento, la integración social se entendió como efecto de una asimilación unilateral (del inmigrante o del extranjero a la cultura «nacional» dominante del país de acogida), la teoría postcolonial (Canclini, Bhaba) insiste, con toda la razón, en la necesidad de superar esta situación de dominación. Según ellos, las culturas cambian mediante una serie de hibridaciones, procesos «mediante los que las anteriormente aisladas estructuras y prácticas discretas generan nuevas estructuras, objetos o prácticas» (Rath, 2010: 145), con lo cual queda demostrado que cualquier fusión de dos elementos distintos ya es la consecuencia de una serie de hibridaciones anteriores. Consideramos, por lo tanto, las parejas mixtas como construcciones sociales que representan uno de estos espacios terciarios donde se producen nuevos híbridos culturales mediante una nueva semántica cultural, a la cual la sociedad se ve obligada a responder mediante los sistemas de comunicación, educación y legislación.

Ahora bien, cualquier investigación científica consigue sus objetivos partiendo de presupuestos heurísticos, así como datos existentes y asequibles. Hay que destacar que los estudios sobre el impacto social y cultural de las parejas mixtas son muy escasos, debido al carácter novedoso del fenómeno comprendido como hecho social masivo ${ }^{12}$. En el presente caso, se trata principalmente de fundamentar el análisis estructural (macrosociológico) a partir de datos estadísticos de varios países significativos de la Unión Europea que, aparte de su valor informativo y heurístico, demuestran la necesidad de un futuro análisis sociológico, tanto cuantitativo como cualitativo, más detenido, mediante el cual explicar el aumento y el impacto de las parejas mixtas como agentes del cambio social y cultural. Profundizar en este hecho social y sus todavía ampliamente desconocidas consecuencias parece especialmente importante con vista a las dificultades actuales surgidas en torno a la integración social, la

12. En uno de los estudios más importantes sobre la inmigración musulmana en Europa, publicado en 2004, no hay referencias significativas respecto a los matrimonios mixtos. Por otro lado, se confirma la importancia de la inmigración como trasfondo social del fenómeno en cuestión. No obstante, la inmigración sólo es una parte del tema: hay que tener en cuenta otros aspectos más de la globalización, como el creciente nivel de comunicación intercultural y los nuevos estilos de vida que influyen en el comportamiento marital. 
cohesión social, la «identidad cultural» y, sobre todo, el cambio cultural en las sociedades occidentales avanzadas.

\section{El auge de los matrimonios mixtos en varios países europeos}

Hemos subrayado, en otro momento y lugar, que uno de los fenómenos sociales destacados de la globalización, sobre todo en los países avanzados, es el aumento de matrimonios o parejas culturalmente mixtos ${ }^{13}$. En la mayoría de los casos, las estadísticas nacionales todavía no reflejan dicho fenómeno de manera adecuada, porque utilizan conceptos arraigados en un pensamiento que define a los ciudadanos exclusivamente a partir de su nacionalidad. De este modo, el mestizaje racial, étnico y cultural queda oculto, a pesar de que, en realidad, se llevan desarrollando procesos significativos de cambio cultural que afectan a muchas dimensiones de la vida y a sectores sociales en las sociedades contemporáneas. El mestizaje, y con ello la presencia de las parejas y los matrimonios mixtos, se puede considerar como un hecho histórico-social recurrente (de más o menos intensidad) en la mayoría de las sociedades, aunque se ha convertido en un dato llamativo sólo a lo largo de la segunda mitad del siglo pasado, especialmente en las dos últimas décadas. A primera vista, se trata de una consecuencia del asentamiento definitivo de un gran número de trabajadores, sin o con sus familias, que llegaron a los países europeos industrializados a lo largo de los últimos cincuenta años buscando empleo y que, desde entonces, de una u otra manera, constituyen una fuente importante del mercado marital y de las interacciones socioculturales. De este modo, en el año 2007, la tasa de matrimonios mixtos en países como Francia, Alemania o Austria ha alcanzado valores de entre el 11,8 y el 18,2\% sobre el total de matrimonios contraídos en lo que va de año. En el caso de España, habría que destacar el espectacular crecimiento de esta tasa, que pasó del 4,1\% en 1996 al $12,9 \%$ en $2007^{14}$ (véase la tabla 1 ).

Esta tendencia está relacionada con los procesos migratorios que contribuyen al carácter multicultural de la mayoría de las sociedades avanzadas, tal como se refleja en la tabla 2.

13. Véase el seminario Parejas binacionales en la sociedad avanzada, organizado por el Centro de Estudios Andaluces y el Departamento de Sociología de la Universidad de Sevilla (Sevilla, 20-21 de mayo de 2009). Definimos como matrimonio mixto y pareja mixta aquellos formados por un cónyuge español y otro extranjero (independientemente de su sexo). Es decir, los matrimonios mixtos forman parte de la población más amplia de las parejas mixtas, pero, debido al carácter no formalizado de éstas, las estadísticas sólo hacen referencia a los matrimonios mixtos. Debido al hecho de que el descenso relativo de los matrimonios se debe en buena parte al aumento de las parejas no formalizadas, nos referimos a todo tipo de parejas mixtas, aunque los datos que se presentan sólo expresan el núcleo formado por los matrimonios mixtos, de modo que se puede decir que la dimensión sociocultural del fenómeno analizado aquí es todavía más amplia: hay más parejas mixtas que matrimonios mixtos.

14. Respecto al caso de Alemania, ver Schroedter y Kalter (2008); al caso de España, ver Alaminos, Albert y Santacreu (2008), Alaminos y Perea (2008), Rodríguez (2006) y Bote (2004). 
Tabla 1. Tasas de matrimonios mixtos sobre el total de matrimonios contraídos, por años y países escogidos (en tantos por ciento)

\begin{tabular}{lrrrr}
\hline Francia & 1997 & 8,7 & 2007 & 13,4 \\
Alemania & 1999 & 13,6 & 2007 & 11,8 \\
Austria & 1995 & 12,8 & 2007 & 18,2 \\
España & 1996 & 4,1 & 2007 & 12,9 \\
\hline
\end{tabular}

Fuente: INED: http://www.ined.fr/fr/pop_chiffres/france/mariages_divorces_pacs/mariages_mixtes; Verband binationaler Familien und Partnerschaften: www.verband-binationaler.de/zahlenundfakten, Statistisches Bundesamt (Natürliche Bevölkerungsbewegung); Statistik Austria 2008; INE: Movimiento natural. Matrimonios, y elaboración propia.

Tabla 2. Población extranjera residente en diferentes países de la Unión Europea (2008, Francia: 2006)

\begin{tabular}{lccc}
\hline País & $\begin{array}{c}\text { Población } \\
\text { (en millones) }\end{array}$ & $\begin{array}{c}\text { Población extranjera residente } \\
\text { (en millones) }\end{array}$ & $\begin{array}{c}\text { Población extranjera del } \\
\text { total de la población (\%) }\end{array}$ \\
\hline Alemania & 82,37 & 10,14 & 12,31 \\
Reino Unido & 60,94 & 5,41 & 8,88 \\
Francia & 61,04 & 6,47 & 10,60 \\
España & 46,16 & 5,27 & 11,40 \\
Austria & 8,21 & 1,23 & 14,98 \\
\hline
\end{tabular}

Fuente: Nationmaster y elaboración propia.

No obstante - aparte de constatar que las tasas de matrimonios mixtos aumentan necesariamente debido al crecimiento de la población extranjera—, para explicar el fenómeno provocado por las transformaciones de las distintas sociedades en el transcurso de la globalización, hace falta distinguir entre la inmigración iniciada por motivos exclusivamente económicos o políticos, por un lado, y el aumento general de la movilidad geográfica, por otro.

Quisiera demostrar aquí hasta qué punto los matrimonios son hechos sociales influenciados por dos tendencias que caracterizan la dinámica cultural en el mundo actual, sobre todo en las sociedades avanzadas. Concretamente, se trata de:

- Las consecuencias de la inmigración de trabajadores extranjeros iniciada en la década de 1960 y que continúa, aunque su origen se traslada a otras regiones económicamente desfavorecidas del mundo.

- La introducción y la difusión de nuevas formas y estilos de vida en el marco de la condición postmoderna, sobre todo en el ambiente de las nuevas clases medias, lo cual facilita los contactos entre las personas, independientemente de las fronteras, los lugares y el tiempo. Esto se debe a las tecnologías de la comunicación y del transporte, que favorecen, además, la ampliación del nivel educativo y cultural.

En la medida en la que la dinámica socioeconómica del capitalismo global ha impuesto al mundo su lógica instrumental peculiar, basada en el valor de cambio, también ha creado a los sujetos actores correspondientes, al desencadenar toda una serie de transformaciones de las actitudes sociales y los estándares culturales. Hoy día, más y más personas superan el espacio y la perspectiva limitada de una cosmovisión nacional ante la posibilidad de encontrar su pareja procedente de 
una cultura diferente. De este modo, uno se acostumbra a vivir la diferencia. El cambio de comportamiento individual y la transformación estructural de la sociedad han generado nuevas posibilidades de interacción sentimental que han conducido a relaciones conyugales entre personas procedentes de culturas muy diferentes, como es el caso de parejas mixtas compuestas por occidentales y musulmanes, con sus peculiaridades nacionales, culturales y religiosas. De este modo, la identificación cultural de los europeos con Occidente ha quedado relativizada como hecho puramente histórico y de ninguna manera debe excluir cualquier futura cultura híbrida basada en el mestizaje de dos esferas distintas. La cuestión es, pues, en qué sentido y cómo establecer esta hibridad transcultural en nuestra vida social. Indudablemente, la intervención política no es una medida efectiva si va encaminada a obstaculizar las tendencias que surgen en la vida social cotidiana. En muchos casos, son las dificultades y las imposiciones a la hora de reconocer los derechos de los cónyuges extranjeros o de conceder el permiso de residencia y la naturalización, las que se contraponen en este sentido. Es en este microcosmos de la sociedad donde encontramos una actividad sociocultural singular que permite establecer relaciones socioemocionales en las que nace la posibilidad de establecer un verdadero diálogo intercultural.

Esto significa que las culturas ya no funcionan como patrimonios exclusivos de sociedades nacionales herméticas, sino más bien como dimensiones simbólicas que permiten crear la comunicación transcultural y la construcción de identidades en coincidencia con las posibilidades y las preferencias de las personas implicadas.

A medida que las culturas vienen a ser más permeables y el panorama cultural más rico, sus consecuencias sociales son más patentes que en el pasado. Por esta razón, el aumento significativo de los matrimonios y las parejas de tipo mixto (binacionales o biculturales) no es un fenómeno accidental o marginal, sino una tendencia que pone de relieve la poderosa influencia de la cultura en la vida social.

Las sociedades avanzadas albergan un número creciente de personas relacionadas con la inmigración (inmigrantes y descendientes de segunda generación) de todo el mundo. Aunque las migraciones no son un fenómeno exclusivamente contemporáneo, hoy día constituyen una de las fuentes de problemas de cohesión e integración social en los países de destino, así como en los países de origen. El significado particular de la importancia de este hecho social relacionado con la globalización provoca el interés de la sociología, debido a su carácter masivo y a su impacto sobre las estructuras y los procesos sociales que subyacen al cambio cultural.

La desconexión entre la esfera política y la del mundo de la vida (Lebenswelt) explica sin duda muchas de las consecuencias sociales y culturales conflictivas que acompañan a la inmigración. Así, mientras que en la esfera política se trata como un problema administrativo, en la esfera del mundo de la vida los conflictos son arreglados en el marco de las interacciones sociales directas. De esta manera, un problema económico (el de la oferta y la demanda de mano de obra barata) se ve transformado en un problema de integración y de orden social, el 
cual, en ciertos casos, ha conducido a la confrontación étnica y al racismo que intenta justificarse con una supuesta incompatibilidad cultural o religiosa. El fracaso de la integración social y de la asimilación unilateral de los inmigrantes a los estándares culturales del país de acogida ha provocado en numerosos casos la segregación entre los diferentes colectivos, de modo que la pretendida multiculturalidad de la sociedad avanzada quedó congelada en el fenómeno de las sociedades paralelas, con todas las consecuencias que esta alienación contrae. En lo que al comportamiento marital se refiere, la oposición a la lógica cultural del «otro» puede producir una actitud defensiva e incluso el rechazo a nivel de la vida cotidiana y reforzar la endogamia como actitud separatista. No obstante, el hecho del creciente número de parejas mixtas rompe este esquema e indica una salida basada en un cambio cultural en el futuro próximo.

Las sociedades multiculturales se han convertido en una fuente de problemas de interacción cultural, debido a la incapacidad de percibir la inmigración como un elemento dinámico para el desarrollo de la sociedad avanzada. El verdadero problema de la integración consiste, pues, en la ausencia de mecanismos de comunicación y de interacción directas que funcionen como generadores potenciales de híbridos transculturales. Podrían constituir una futura base de relaciones sociales que responden mejor a la dimensión multicultural de este tipo de sociedad.

\section{Los casos de España y Andalucía}

Ahora bien, se trata de aplicar nuestras reflexiones a una situación concreta y presentar algunos datos que iluminen el desarrollo de los matrimonios mixtos binacionales o biculturales en España y, particularmente, en Andalucía durante las últimas dos décadas, cuando la inmigración se convirtió en la fuente principal del aumento de estas parejas.

En primer lugar, se mostrará la evolución de las tasas de inmigración y, a continuación, la de los matrimonios mixtos. Por último, serán analizadas las preferencias en la elección del cónyuge y los cambios que muestran en estos años.

\subsection{La evolución de las tasas de inmigrantes en España y en Andalucía}

Las estadísticas oficiales no distinguen entre la población autóctona y las demás, que conservan (excepto en el caso de ser naturalizadas y asimiladas) sus raíces culturales de origen. Por esta razón, es necesario proceder a un reagrupamiento de las diferentes poblaciones independientemente de su nacionalidad, es decir, diferenciar entre los sectores de la población extranjera residente y la de los inmigrantes naturalizados.

Como podemos ver, en el año 2008, la población española incluía más de 6 millones de personas nacidas en el extranjero, de las cuales casi 5,3 millones conservaron su nacionalidad de origen, mientras que algo más de un millón de nacidos en el extranjero poseen la nacionalidad española o han sido naturalizados. Por otro lado, de los extranjeros nacidos en España, 261.897 personas 
Tabla 3. Composición de la población española según nacionalidad, lugar de nacimiento y trasfondo cultural (2008)

\begin{tabular}{lcc}
\hline Personas / población & Total & Total (\%) \\
\hline Nacidos en España: & 40.113 .294 & \\
- Con la nacionalidad española & 39.851 .397 & 86,90 \\
- Con una nacionalidad extranjera (a) & $261.897^{\star}$ & $(0,57)$ \\
\hline Nacidos en el extranjero: & 6.044 .528 & \\
- Con la nacionalidad española (c) & 1.037 .663 & 13,10 \\
- Con una nacionalidad extranjera (b) & $5.006 .865^{\star}$ & $(2,25)$ \\
Total población & 46.157 .822 & 100,00 \\
\hline Total población con una nacionalidad extranjera (a + b) & $5.268 .762^{\star}$ & 11,41 \\
\hline Total población con un trasfondo cultural extranjero $=$ & 6.306 .425 & 13,66 \\
- Personas nacidas en España pero con nacionalidad & & \\
$\quad$ extranjera (a). & & \\
- Personas nacidas en el extranjero y con una nacionalidad & & \\
$\quad$ extranjera (b). & & \\
- Descendientes de extranjeros nacidos en España y con & & \\
$\quad$ nacionalidad española (c). & & \\
\hline
\end{tabular}

Fuente: INEbase.

conservaron su nacionalidad de origen. Teniendo en cuenta que la población extranjera en España en aquel año ascendió al 11,41\% del total de la población del país y que a esta cantidad habría que sumar 1.037.663 inmigrantes naturalizados, se obtendría un total de 6.306 .425 personas (o un 13,67\% de la población total de más de 46 millones) con un trasfondo migratorio, sin contar la segunda generación de los inmigrantes. Por todo esto, se llega a la conclusión de que la población con trasfondo cultural extranjero es superior a la indicada por la estadística a consecuencia de las naturalizaciones. No cabe duda de que, a nivel étnico-cultural, independientemente de la nacionalidad, la cantidad de inmigrantes de la primera y de la segunda generaciones es importante para definir las categorías sociales afectadas por el proceso de interacción sociocultural entre los diferentes colectivos, al igual que por la hibridación transcultural y los conflictos que esta puede significar. Esta dialéctica se refleja en la siguiente cita:

España ha pasado a ser uno de los primeros países en recepción de inmigrantes de la Unión Europea y si bien es cierto que todavía estamos lejos de las cifras de otros países, como la misma Francia, Alemania, también lo es que nuestro ritmo de crecimiento es muy rápido y puede generar un asentamiento de esta nueva población en forma de aluvión con escasas perspectivas de integración.

Por otra parte, no puede ignorarse que los conflictos más graves tienden a producirse no tanto en la primera generación de inmigrantes, sino en sus hijos, si el proceso de socialización con la sociedad receptora está mal hecho. El caso de los magrebíes en Francia es bien evidente en este sentido. (AGEANET, $\mathrm{La}$ inmigración en España) ${ }^{15}$

15. http://www.agea.org.es/20041228267/la-inmigracion-en-espana.html. Consulta: 25 de enero de 2010. 
Tabla 4. Población extranjera en Andalucía según la nacionalidad (1991, 1998 y 2008)

\begin{tabular}{|c|c|c|c|c|c|c|c|c|c|c|c|}
\hline \multirow[b]{2}{*}{ Año } & \multicolumn{2}{|c|}{$\begin{array}{l}\text { Población } \\
\text { andaluza }\end{array}$} & \multicolumn{2}{|c|}{$\begin{array}{l}\text { Población nacida } \\
\text { en el extranjero }\end{array}$} & \multicolumn{2}{|c|}{$\begin{array}{l}\text { Población con } \\
\text { la nacionalidad } \\
\text { extranjera }\end{array}$} & \multicolumn{2}{|c|}{$\begin{array}{l}\text { Inmigrantes y sus } \\
\text { descendientes } \\
\text { naturalizados } \\
\text { españoles }\end{array}$} & \multicolumn{3}{|c|}{$\begin{array}{l}\text { Población andaluza con un } \\
\text { fondo migratorio extranjero }\end{array}$} \\
\hline & Total & $\%$ & Total & $\%$ & Total & $\%$ & Total & $\%$ & Total & $\%$ & \% España \\
\hline 1991 & 6.940 .522 & 100 & 61.670 & 0,89 & - & - & - & - & 61.670 & 0,89 & - \\
\hline 1998 & 7.236 .459 & 100 & 182.693 & 2,52 & 161.275 & 2,23 & 86.294 & 1,19 & 247.569 & 3,42 & 2,95 \\
\hline 2008 & 8.202 .220 & 100 & 725.819 & 8,85 & 623.279 & 7,60 & 128.214 & 1,56 & 751.493 & 9,16 & 13,66 \\
\hline
\end{tabular}

Fuente: Anuario Estadístico de Andalucía, 1996; Inmigración Extranjera en Andalucía, 1991-2001; Instituto de Estadísticas de Andalucía (IEA), 1991, 2008; Padrón Municipal revisado, 2008.

En el caso de Andalucía, la situación es parecida (tabla 4):

El boom de la inmigración en el territorio español se inició hacia finales de la década de 1990, pero la tasa de extranjeros residentes en el país que habían nacido en otro aumentó espectacularmente entre 1998 y 2008, puesto que pasó del 2,95\% al 13,66\%. En Andalucía, la misma tasa muestra un incremento inferior, sólo del 2,52\% al 8,85\%, lo que se debe a la falta de atracción económica de la región y a su estatus de "tierra de paso» de los inmigrantes a las zonas del país con más demanda de mano de obra ${ }^{16}$. Pero estas estadísticas, diseñadas para el modelo de las sociedades nacionales y no para las sociedades multiculturales, no son del todo viables, porque, en ellas, no se distingue entre los inmigrantes extranjeros residentes en España y los ciudadanos españoles nacidos en el extranjero. Tampoco tiene en consideración los inmigrantes nacidos en el extranjero pero naturalizados en España. Aunque las estadísticas actuales indican el lugar de nacimiento y/o la nacionalidad de las personas, estos datos no reflejan fielmente su trasfondo cultural, es decir, el carácter intersectorial o híbrido de la constitución cívica y cultural de la población de inmigrantes. Por esta razón, habría que definir la población residente española con un trasfondo cultural extranjero a partir de las siguientes tres categorías de inmigrantes de ambos sexos:

— Los inmigrantes nacidos en el extranjero (la "primera generación» de inmigrantes).

- Los ciudadanos españoles nacidos en el extranjero.

- Los inmigrantes naturalizados españoles.

Esto quiere decir que ser inmigrante no significa necesariamente ser extranjero, sobre todo si se piensa en la segunda generación de inmigrantes, ya que, como descendientes de inmigrantes, o bien pueden conservar la nacionalidad

16. La inmigración de extranjeros a Andalucía aumentó sólo a partir del segundo semestre de 1996, según el Instituto de Estadística de Andalucía (Estadística de Variaciones Residenciales: Inmigración Extranjera en Andalucía 1991-2001, p. 18, gráfico 1.2.2.2). No obstante, a partir de finales del año 1995, se incrementó también la emigración de la región hacia el resto de España, con lo cual se superó el número de inmigrantes que llegaron a la región sureña (ibídem: gráfico 1.2.2.3). 
de sus padres pero asimilar la cultura española, o bien ser naturalizados españoles y seguir conservando sus raíces culturales originarias.

En el caso de Andalucía, se observa una tendencia parecida aunque menos pronunciada: aunque la población extranjera aumentó al décuplo a lo largo de los últimos diez años, puesto que llegó a más de 623.000 personas, la tasa del $7,60 \%$ es claramente inferior comparada con la del territorio nacional. Esto se explica, quizás, por el hecho de que Andalucía es, sin duda, una región muy atractiva para los turistas, pero menos interesante para los inmigrantes que llegan por motivos laborales y que prefieren las aglomeraciones socioeconómicas de Madrid, Barcelona o Valencia.

Por otro lado, el aumento de la población extranjera también es la consecuencia política de una reducción de la tasa de naturalizaciones de los inmigrantes, que decayó del 47,8\% en 1998 al 19,2\% en 2007.

En fin, el conjunto de inmigrantes con nacionalidad extranjera y aquellos (incluyendo sus descendientes) que han conseguido la nacionalidad española asciende a más de 750.000 personas o el 9,16\% del total de la población andaluza (13,66\%, en el caso del total de la población española), a los que se puede adscribir un trasfondo cultural extranjero, si se tiene en cuenta que los valores y los hábitos culturales no cambian bruscamente con la adquisición de otra nacionalidad.

Respecto al origen de los inmigrantes, se puede observar una significativa reestructuración interna: mientras que, en 1998, la mitad (el 50,8\%) de los inmigrantes vino de países de la UE y el 26,8\% de un país africano, en 2007, la tendencia ha cambiado a favor de los países europeos no comunitarios (del Este) y de América del Sur (22,8\%). En el mismo periodo, el peso de los inmigrantes africanos disminuyó.

Sea como sea, los hechos demuestran claramente que, en sólo diez años, España se ha transformado de un país de emigrantes en un país de inmigrantes, con una de las tasas más altas entre los países de la Comunidad Europea. Es necesario recordar que la base económica de este boom social fue la situación creada por la especulación inmobiliaria iniciada a mitad de la década de 1990 por el gobierno conservador de José María Aznar, un hecho que estimuló el sector de la construcción hasta el 2008 y creó una demanda de mano de obra de casi un millón de personas, del que casi la mitad se reclutó entre los inmigrantes. Hoy en día, la caída de este sector se considera una de las causas más importantes de la actual crisis económica en España, lo cual ha acentuado los problemas sociales y culturales en relación con los inmigrantes.

No obstante, aunque el aumento espectacular de parejas mixtas se puede atribuir en gran parte al aumento espectacular de la población inmigrante, el fenómeno no se puede relacionar únicamente con la inmigración. Con independencia del número de inmigrantes, la situación de España en general y de Andalucía en concreto refleja las tendencias socioculturales generales de la globalización, es decir, un cambio significativo del comportamiento hacia el matrimonio, tal como se puede observar también en el caso de los matrimonios mixtos. Ya que los inmigrantes naturalizados no son considerados en las 
estadísticas referentes a los matrimonios mixtos, se puede concluir que, adicionalmente a la categoría de parejas mixtas, existen matrimonios culturalmente mixtos, aunque oficialmente considerados como matrimonios entre españoles. Es decir, hay más parejas culturalmente mixtas que parejas binacionales. La nacionalidad constituye, pues, un indicador dudoso e inexacto cuando se trata de analizar los matrimonios mixtos.

\subsection{La evolución de la tasa de matrimonios mixtos en España y en Andalucía (1991-2008)}

A continuación, se analizará el desarrollo de las tasas de matrimonios mixtos en España y en Andalucía a partir de las estadísticas oficiales sobre matrimonios mixtos de sexos diferentes.

Entre 1996 y 2007, el número total de matrimonios heterosexuales en el marco de la población española mostró una tendencia hacia la inestabilidad: en 2007, sólo superó ligeramente la tasa de once años antes. Pero, en el mismo periodo, las tasas de matrimonios mixtos se han triplicado hasta el 13\% del total de matrimonios en 2007. Aun así, las tasas no incluyen los matrimonios mixtos contraídos fuera de España y tampoco los de entre personas del mismo sexo. Lo que sí se puede destacar es que, a partir de 1998, la actitud hacia el matrimonio mixto se está "masculinizando»: los varones españoles (más que las mujeres) comienzan a mostrar un creciente interés por una cónyuge extranjera.

En Andalucía, la tendencia es similar: aunque el número total de matrimonios apenas aumentó en el mismo periodo en trescientos casos $(0,7 \%)$, la tasa

Tabla 5. Matrimonios heterosexuales en España con uno de los cónyuges extranjero (1996-2007)

\begin{tabular}{cccccc}
\hline Año & $\begin{array}{c}\text { Marido español, } \\
\text { esposa } \\
\text { extranjera }\end{array}$ & $\begin{array}{c}\text { Esposa } \\
\text { española, } \\
\text { marido } \\
\text { extranjero }\end{array}$ & $\begin{array}{c}\text { Total } \\
\text { matrimonios } \\
\text { mixtos }\end{array}$ & $\begin{array}{c}\text { Total } \\
\text { matrimonios }\end{array}$ & $\begin{array}{c}\text { Matrimonios } \\
\text { mixtos (\%) }\end{array}$ \\
\hline 1996 & 3.568 & 4.441 & 8.009 & 194.084 & 4,13 \\
1997 & 3.709 & 4.443 & 8.152 & 196.499 & 4,15 \\
1998 & 4.496 & 4.771 & 9.267 & 207.041 & 4,48 \\
1999 & 5.137 & 4.924 & 10.061 & 208.129 & 4,83 \\
2000 & 5.316 & 4.985 & 10.301 & 216.451 & 4,76 \\
2001 & 6.517 & 5.237 & 11.754 & 208.057 & 5,65 \\
2002 & 8.329 & 6.039 & 14.368 & 211.522 & 6,79 \\
2003 & 11.349 & 7.739 & 19.088 & 212.300 & 8,99 \\
2004 & 13.574 & 9.074 & 22.618 & 216.149 & 10,46 \\
2005 & 13.672 & 8.730 & 22.402 & 208.146 & 10,76 \\
2006 & 14.499 & 9.420 & 23.919 & 203.453 & 11,76 \\
2007 & 15.395 & 10.659 & 26.054 & 201.579 & 12,92 \\
\hline
\end{tabular}

Fuente: INE (Movimiento natural. Matrimonios), Anuario Estadístico de Inmigración, Observatorio del Ministerio de Asuntos Sociales, y elaboración propia. 
Tabla 6. Matrimonios mixtos en Andalucía (1999-2007)

\begin{tabular}{cccccccc}
\hline & & \multicolumn{2}{c}{ Matrimonios mixtos } & & \multicolumn{2}{c}{ Con un cónyuge español } \\
\cline { 6 - 7 } Año & Total matrimonios & & Total & $\%$ & & Total & $\%$ \\
\hline 1999 & 41.577 & 1.175 & 2,82 & & 1.071 & 2,56 \\
2007 & 41.856 & 4.333 & 10,35 & & 3.489 & 8,33 \\
\hline
\end{tabular}

Fuente: Instituto de Estadísticas de Andalucía, y elaboración propia.

Tabla 7. Evolución de las tasas de matrimonios mixtos con un cónyuge español en España y en Andalucía, 1999 y 2007 (en tantos por ciento)

\begin{tabular}{ccc}
\hline Año & España & Andalucía \\
\hline 1999 & 4,83 & 2,56 \\
2007 & 12,92 & 8,33 \\
\hline
\end{tabular}

Fuente: elaboración propia a partir de las tablas 5 y 6 .

referente a los matrimonios mixtos subió del 2,8\% al 10,4\%, y en el caso de aquellos con un cónyuge español se triplicó del 2,6\% al 8,3\%.

La comparación de la tasa andaluza con la tasa de toda España muestra una actitud menos favorable hacia el matrimonio mixto en Andalucía, lo cual responde, quizás, al hecho de la existencia de una tradición endogámica regional más fuerte, como consecuencia de su particular estructura social, su regionalismo, los lazos familiares y los valores religiosos locales.

En el caso de Andalucía, el incremento relativo de los matrimonios mixtos se debe, como se puede ver más abajo, al aumento del interés masculino por encontrar una esposa extranjera. Por esta razón, se podría concluir que los datos estadísticos indican unos cambios en la actitud respecto al matrimonio que afecta al comportamiento en general, pero también a su estructura interna según el género.

\subsection{La evolución de las preferencias en la elección de los cónyuges extranjeros}

La elección subjetiva del cónyuge está habitualmente influenciada por los estándares culturales en vigor, tanto en el país de recepción como en el país de origen de los inmigrantes. Estos estándares se manifiestan en tres niveles:

a) En el nivel de las preferencias individuales basadas en la definición mutua de los cónyuges, hecho que se realiza a partir de su capital cultural, de sus actitudes y de sus orientaciones, compartidas en estrecha relación con su capacidad lingüística.

b) En el nivel de los grupos sociales de referencia que deciden sobre el reconocimiento o el rechazo del otro cónyuge «extranjero» y que pueden servir como puentes entre las dos culturas implicadas, siempre y cuando los dos cónyuges acepten su autoridad.

c) En el nivel de las condiciones estructurales del mercado marital parcial que favorecen las ocasiones del encuentro, como son, por ejemplo, las escuelas, los lugares de trabajo, las asociaciones civiles, la vecindad, las agencias 
de contacto e Internet, las cuales, además, dependen del tamaño y de la importancia del grupo étnico de origen.

Las tablas siguientes nos informan sobre la estructura interna de los matrimonios mixtos heterosexuales en España y en Andalucía según el origen del cónyuge extranjero y las preferencias en la elección.

Destaca el fuerte incremento de los matrimonios formados entre un español o una española y un cónyuge procedente de un país de América del Sur o Central. Habría que añadir que, en estos casos, el cónyuge español podría ser, en muchos casos, un inmigrante naturalizado del mismo origen, por lo cual no se puede considerar como matrimonios mixtos según nuestra definición, es decir, en el sentido cultural.

Tabla 8. Matrimonios heterosexuales en España con un cónyuge extranjero según el lugar de nacimiento 1996-2007 (sin Oceanía)

\begin{tabular}{ccccccccc}
\hline & & \multicolumn{2}{c}{ África } & & \multicolumn{2}{c}{ América } & & \\
\cline { 3 - 4 } Año & Europa & Total & Marruecos $^{*}$ & Total & EE.UU. & & Asia & \multicolumn{1}{c}{ Total } \\
\hline 1996 & 3.353 & 1.516 & 1.209 & 2.726 & 316 & 381 & 8.009 \\
1997 & 3.357 & 1.492 & 1.148 & 2.836 & 320 & 454 & 8.152 \\
1998 & 3.706 & 1.573 & 1.167 & 3.438 & 288 & 503 & 9.267 \\
1999 & 2.451 & 1.121 & 1.361 & 3.944 & 319 & 345 & 10.061 \\
2000 & 4.254 & 1.594 & 1.161 & 4.103 & 338 & 315 & 10.301 \\
2001 & 4.515 & 1.587 & 1.079 & 5.285 & 295 & 290 & 11.754 \\
2002 & 4.978 & 1.744 & 1.117 & 7.252 & 342 & 327 & 14.368 \\
2003 & 5.930 & 2.420 & 1.668 & 10.246 & 353 & 446 & 19.088 \\
2004 & 6.834 & 2.999 & 1.977 & 12.213 & 324 & 554 & 22.618 \\
2005 & 6.985 & 2.949 & 1.820 & 11.803 & 318 & 611 & 22.402 \\
2006 & 7.331 & 3.136 & 2.012 & 12.674 & 217 & & 716 & 23.019 \\
2007 & 6.824 & 4.053 & 2.437 & 14.239 & 322 & & 866 & 26.054 \\
Incremento (\%) & 103,52 & 167,34 & 101,57 & 422,34 & 1,90 & 127,30 & 225,31 \\
\hline
\end{tabular}

* A partir de 2005 con Argelia.

Fuente: INE (INEbase), Matrimonios de extranjeros, y elaboración propia.

Tabla 9. Preferencias de hombres españoles en la elección de una esposa extranjera según su origen (1996 y 2007)

\begin{tabular}{|c|c|c|c|c|}
\hline \multirow[b]{2}{*}{ Origen de la esposa } & \multicolumn{2}{|c|}{1996} & \multicolumn{2}{|c|}{2007} \\
\hline & Abs. & $\%$ & Abs. & $\%$ \\
\hline América del sur o central & 1.745 & 48,9 & 9.901 & 64,3 \\
\hline Europa & 1.197 & 33,6 & 3.765 & 24,5 \\
\hline África & 500 & 14,0 & 1.417 & 9,2 \\
\hline Asia & 114 & 3,2 & 288 & 1,9 \\
\hline Resto del mundo & - & - & - & - \\
\hline Esposas extranjeras & 3.568 & 100 & 15.395 & 100 \\
\hline Esposas extr. / Total matr. Mixtos & $N=8.009$ & 44,55 & $N=26.054$ & 59,01 \\
\hline
\end{tabular}

Fuente: Instituto Nacional de Estadística, y elaboración propia. 
Tabla 10. Preferencias de las mujeres españolas en la elección de un marido extranjero según su origen (1996 y 2007)

\begin{tabular}{lrrrrr}
\hline & \multicolumn{2}{c}{1996} & & \multicolumn{2}{c}{2007} \\
\cline { 2 - 3 } \cline { 5 - 6 } Origen del marido & \multicolumn{1}{c}{ Abs. } & $\%$ & & \multicolumn{1}{c}{ Abs. } & $\%$ \\
\hline Europa & 2.156 & 48,5 & & 3.059 & 28,7 \\
África & 1.016 & 22,8 & & 2.636 & 24,7 \\
América del sur o central & 981 & 22,3 & & 4.338 & 40,7 \\
Asia & 267 & 6,0 & & 578 & 5,4 \\
Resto del mundo & - & - & & - & \\
Marido extranjero & 4.441 & 100 & & 10.659 & 100 \\
Marido extr. / Total matr. Mixtos & $\mathrm{N}=8.009$ & 55,45 & & $\mathrm{~N}=26.054$ & 40,91 \\
\hline
\end{tabular}

Fuente: Instituto Nacional de Estadística, y elaboración propia.

La comparación de los diferentes comportamientos maritales en la elección del cónyuge según el sexo muestra tres características específicas en el periodo observado:

a) Una masculinización, en cuanto que la tasa de hombres españoles que eligen una esposa extranjera se incrementó, mientras que la tasa de mujeres españolas que eligen un marido extranjero disminuyó.

b) Una latinización o una fuerte tendencia hacia la elección de un cónyuge de origen sudamericano.

c) Una homogeneización de los géneros en la medida en la que sus preferencias se asemejan, puesto que se centran en las mismas regiones del mundo, es decir, en un país europeo o de América del Sur, aunque las mujeres españolas siguen mostrando más interés en los magrebíes que sus conciudadanos masculinos.

La situación es parecida en el caso de Andalucía (tabla 11).

Según estos datos referentes a Andalucía, el número de los matrimonios mixtos ha aumentado entre 1999 y 2007 en un 243,3\%, puesto que ha pasado de 1.175 a 4.333 casos. Respecto a los matrimonios mixtos con la participación de un cónyuge español, el aumento es de 1.071 a 3.489 casos $(+225,7 \%)$. En este periodo, la participación de los matrimonios formados por dos cónyuges españoles ha disminuido, como se puede deducir a partir de los datos (ver tabla 6). Este cambio se explica, por lo menos parcialmente, por el aumento de inmigrantes y la ampliación cuantitativa del mercado marital formado por extranjeros de ambos sexos, pero también por la naturalización de una parte de los inmigrantes que convierte un cónyuge extranjero en español y, como consecuencia, una pareja en «mixta». Por un lado, el aumento de las tasas de inmigrantes aumenta el número de matrimonios mixtos debido a los matrimonios formados por dos cónyuges extranjeros de procedencia regional diferente. Por otro lado, la naturalización de extranjeros ha convertido en matrimonio mixto una pareja formada por cónyuges procedentes del extranjero, incluso del mismo país, aunque formado ahora por un cónyuge 
Tabla 11. Matrimonios mixtos en Andalucía ( $N$ ) con participación de un cónyuge español (n), según las preferencias regionales en la elección del cónyuge (1999 y 2007)

\begin{tabular}{|c|c|c|c|c|c|c|c|c|c|}
\hline \multirow{2}{*}{$\begin{array}{l}1999 \\
N=1.175 \\
N=1.071\end{array}$} & \multicolumn{9}{|c|}{ Nacionalidad del cónyuge extranjero } \\
\hline & África & $\begin{array}{l}\text { América } \\
\text { Central }\end{array}$ & $\begin{array}{l}\text { América } \\
\text { del Sur }\end{array}$ & $\begin{array}{l}\text { América } \\
\text { del Norte }\end{array}$ & Asia & Europa & Oceanía & Total & $\%$ \\
\hline Esposa española & 207 & 22 & 45 & 49 & 24 & 193 & 2 & 542 & 46,1 \\
\hline Marido español & 118 & 26 & 176 & 15 & 19 & 172 & 3 & 529 & 45,0 \\
\hline $\begin{array}{l}2007 \\
N=4.333 \\
n=3.489\end{array}$ & África & $\begin{array}{c}\text { América } \\
\text { Central }\end{array}$ & $\begin{array}{l}\text { América } \\
\text { del Sur }\end{array}$ & $\begin{array}{l}\text { América } \\
\text { del Norte }\end{array}$ & Asia & Europa & Oceanía & Total & $\%$ \\
\hline Esposa española & 504 & 53 & 363 & 32 & 34 & 348 & 2 & 1.336 & 30,8 \\
\hline Marido español & 291 & 150 & 884 & 73 & 35 & 717 & 32 & 2.153 & 49,7 \\
\hline
\end{tabular}

Fuente: Instituto de Estadísticas de Andalucía, y elaboración propia.

español y otro extranjero. Como se puede ver, las estadísticas no reflejan la realidad en este sentido.

Respecto al caso de los cónyuges andaluces, el comportamiento marital también ha cambiado en función del sexo: si, en 1999, el mercado marital se repartió de una manera casi equivalente entre hombres y mujeres (un 45,0\% y un 46,13\%), la tasa de la participación masculina pasó al 50\% en 2007, mientras que la de las andaluzas disminuyó al 30,8\%. Con esto queda demostrado que, también en el caso de Andalucía, el mercado marital destaca una clara tendencia hacia la masculinización.

Además, las preferencias de los varones andaluces en la elección de una esposa extranjera se inclinan, como en el caso de España en general, hacia América Latina, seguido por las europeas y, en menor medida, las africanas (procedentes sobre todo del Magreb). La elección del marido extranjero por parte de las andaluzas también sigue a la tendencia general, al disminuir las preferencias por un marido africano en favor de uno europeo o latinoamericano.

Resumiendo: tanto en el caso de España en general como en el de Andalucía en particular, los varones muestran una clara preferencia por las latinoamericanas, mientras que las mujeres se orientan hacia los países europeos. Debido a que la variable lingüística no explica la diferencia entre los sexos, una posible respuesta podría ser que los españoles se sienten más atraídos por un tipo de mujer supuestamente más tradicional o "femenina», mientras que las mujeres españolas que deciden elegir un marido extranjero buscan una alternativa al modelo de masculinidad tradicional, creyendo que lo encuentran en un marido con trasfondo cultural europeo, es decir, moderno. Esta orientación explicaría, además, la disminución de las preferencias por los magrebíes, aunque este sector del mercado marital aún llama la atención de las mujeres debido a la distorsión del mercado marital parcial magrebí, como consecuencia de la escasez de mujeres núbiles procedentes del Norte de África. La situación de los andaluces que buscan una esposa extranjera es bien diferente: el mercado marital formado por mujeres magrebíes es insignificante y, debido a razones culturales, de difícil acceso para los hombres. 


\section{Conclusiones}

Tanto en España como en Andalucía, las tasas de matrimonios mixtos han aumentado considerablemente a lo largo de los últimos doce años. Las razones y el desarrollo de este fenómeno están íntimamente vinculados con el aumento de la población inmigrante de ambos sexos en este país. Destaca por encima de todo la procedente del Magreb, de América Latina y de Europa. Con esto, España en general y Andalucía en particular se encuentran en una situación bien conocida en los demás países de la Comunidad Europea. Las diferencias respecto a estos, tal como se expresa sobre todo en las preferencias de elección del cónyuge, parecen obedecer menos al orden estructural que a las peculiaridades específicas del país basadas en la situación geográfica, histórica y cultural de la península Ibérica. Independientemente de ello, la situación actual en España muestra un hecho importante que diferencia su caso del de los principales países de inmigración en Europa: el de la dislocación en el tiempo, es decir, de la tendencia tardía hacia una inmigración masiva y, consecuentemente, la reciente aparición de un mercado marital pluricultural. Como resultado de todo ello, se abre la posibilidad de establecer una regulación política y administrativa que debe tener en cuenta las experiencias de aquellos países que se ven confrontados con el mismo fenómeno desde hace más tiempo.

El leitmotiv para una política eficaz en este sentido debería orientarse hacia el hecho de que todas las sociedades avanzadas se están transformando en entidades multiculturales y que los matrimonios mixtos constituyen una manifestación, entre otras, de esta condición.

De la misma manera, habría que admitir que las sociedades avanzadas se desarrollan a partir de un tipo de sistema social anclado en poblaciones diversas con diferentes trasfondos culturales, étnicos y religiosos, de los que se desprenden actitudes y valores a veces opuestos y conflictivos. Por todas estas razones, las sociedades multiculturales son sociedades muy complejas que se enfrentan a serios problemas y a retrocesos políticos respecto a la integración social como base de la cohesión social.

Finalmente, se ha demostrado que el enfoque institucionalista, basado en la familia y su papel en la sociedad, no explica suficientemente estos procesos, debido a los profundos cambios a los que aquella se halla sometida como grupo primario en proceso de adaptación a las nuevas pautas culturales emergentes bajo la influencia de la globalización.

Pero, ¿es realmente posible la integración social en una sociedad compuesta por culturas a veces tan diferentes? ¿Es la diversidad cultural una base sólida que permite superar las diferencias entre las orientaciones y los valores existentes, o se trata más bien de crear las condiciones para una negociación democrática de unas nuevas reglas sociales, transculturales? En el caso de los matrimonios mixtos, es evidente que la multiculturalidad no puede resolver los problemas de la integración social. La multiculturalidad es, en efecto, una parte del problema mismo que no puede ser resuelto en el mismo nivel de la lógica del sistema, sino que exige el reconocimiento de la dinámica que se desarrolla en el mismo mundo de la vida, que es el lugar decisivo donde se produce la 
realidad social cotidiana. Es aquí donde cabe clasificar el papel y la importancia de los matrimonios mixtos como un microsistema social en el que los actores sociales negocian directamente una convención para la cohabitación basándose en sus diferencias culturales y sus biografías individuales.

En el caso de los matrimonios mixtos, la sociología debería reconocer la importancia de la interacción simbólica como proceso en el que se construyen aquellas diversas concepciones de la vida, y donde la creación, la aplicación y la asimilación de nuevas orientaciones y actitudes permiten garantizar la cohabitación social.

\section{Referencias bibliográficas}

Alaminos Chica, Antonio y Perea Crespo, Ignacio (2008a). «Construcción de identidades fronterizas en el seno de las familias multiculturales». Gazeta Internacia de Antropologio, 1 (2). [http://antropologia.umh.es/GIA/index.htm]

Alaminos Chica, Antonio; Perea Crespo, Ignacio; Albert Guardiola María Carmen y SANTACREU FernÁNDEZ, Óscar (2008b). "¿Son los matrimonios mixtos un espacio de construcción intercultural?». Gazeto Internacia Antropologio, 1 (2). [http://antropologia.umh.es/GIA/index.htm]

Anuario Estadístico de Inmigración. Madrid: Observatorio del Ministerio de Asuntos Sociales. [http://extranjeros.mtas.es/es/InformacionEstadistica/Anuarios/Anuario2008.html]

BECKER, Howard S. y MCCALL, Michal M. (eds.) (1990). Symbolic Interaction and Cultural Studies. Chicago y Londres: The University of Chicago Press.

BEDORF, Thomas (2010). «Der Dritte als Scharnierfigur. Die Funktion des Dritten in sozialphilosophischer und ethischer Perspektive». En: EssLinger, Eva; SCHLECHTRIEMEN, Tobias; SCHWEITZER, Doris y Zos, Alexander (eds.). Die Figur des Dritten: Ein kulturwissenschaftliches Paradigma. Berlín: Suhrkamp, 125-136.

Berger, Peter y Luckmann, Thomas (1999). La construcción social de la realidad. Buenos Aires: Amorrortu.

Bericat Alastuey, Eduardo (2007). La valoración social del multiculturalismo y del monoculturalismo en Europa. Documentos de Trabajo S2007 / 01. Sevilla: Fundación Centro de Estudios Andaluces.

BhabHA, Homi (1994). The Location of Culture. Londres: Routledge. Versión castellana: El lugar de la cultura. Buenos Aires: Ediciones Manantial, 2002.

BOROBIO, Dionisio (coord.) (2003). Familia e interculturalidad. Salamanca: Universidad Pontificia de Salamanca.

Bote DíaZ, Marcos Alonso (2004). «Tendencias actuales de la nupcialidad en España: hacia un mercado matrimonial multicultural». Praxis Sociológica, 8, 154-176.

CAMPO, Salustiano del (2003). «Multiculturalismo, inmigración y familia». En: BoroBIO, Dionisio (coord.), op. cit., 197-213.

Centro de Estudios Andaluces. Consejería de la Presidencia. Junta de AndaLUCíA. Seminario Parejas binacionales en la sociedad avanzada: realidades y tendencias de la hibridación transcultural. [http://www.centrodeestudiosandaluces.es/ index.php? $\bmod =$ factoriaideas \&cat $=1 \& \mathrm{id}=73 \& \mathrm{\& ida}=0 \& \mathrm{idm}=$ ]

Cortina, Clara; EsTeve, Albert y Domingo, Andreu (2007). Nupcialidad y características de los matrimonios de las personas de nacionalidad extranjera en España, 1989-2004. Barcelona: Centre d'Estudis Demogràfics. 
Donati, Pierpaolo (2003). Manual de sociología de la familia. Pamplona: Eunsa.

Featherstone, Mike y Lash, Scott (eds.) (1999). Spaces of Culture. City-NationWorld. Londres-Thousand Oaks-Nueva Delhi: SAGE.

GARCÍA CANCLINI, Néstor (2001). Culturas hibridas: Estrategias para entrar y salir de la modernidad. Barcelona: Paidós.

GEERTZ, Clifford (2000). La interpretación de las culturas. Barcelona: Gedisa.

Giménez Romero, Carlos (2003). «Familias en la inmigración: su integración con la sociedad receptora». En: BOROBIO, Dionisio (coord.), op. cit., 129-195.

GORDON, Albert I. (1964). Intermarriage: Interfaith, Interrracial, Interethnic. Boston: Beacon Press.

GuAldA, Estrella y HeRnÁNDEZ, Marta (s.a.). "La construcción social del "extranjero inmigrante”: Definiciones y creencias de los escolares onubenses». Manuscrito redactado en el marco del proyecto Actitudes hacia extranjeros: Huelva y municipios agrícolas, 2005-2006.

HaLLER, Max (1999). Soziologische Theorie im systematisch-kritischen Vergleich. Opladen: Leske+Budrich.

HannerZ, Ulf (1992). Cultural Complexity: Studies in the Social Organization of Meaning. Nueva York: Columbia University Press.

Institut National D’études Démographiques INED. Marriages mixtes. [http:// www.ined.fr/fr/pop_chiffres/france/mariages_divorces_pacs/mariages_mixtes]

Instituto Nacional De Estadística: Matrimonios. Datos nacionales 1996-2007. [http://www.ine.es/taxi/tabla.do, consulta: 18 de marzo de 2009]

Matrimonios. Matrimonios de extranjeros. 1996-2007. [http://www.ine.es/jaxi/tabla.do]

Revisión del padrón municipal 2008. Datos a nivel nacional, comunidad autónoma y provincia. Población extranjera por sexo, país de nacimiento y edad (hasta 85 y más).

[http://www.ine.es/jaxi/tabla.do]

Instituto de Estadísticas de Andalucía (IEA). Consejería de ECONOMía y HACIENDA (2002). Inmigración extranjera en Andalucía 1991-2001. Sevilla, especialmente tabla 3.1.1. «Población extranjera residente»; anexo 2, datos de base, 2.2. «Padrón de habitantes», tabla 2.2.1. «Población inmigrante nacida en el extranjero por sexo y lugar de nacimiento, según nacionalidad. Andalucía», 1998, 2007.

- Anuarios estadísticos 2004, 2005, 2006, 2007 y 2008: «Aspectos dinámicos. Movimiento natural de la población y migraciones».

Kalmijn, Matthijs (1991). "Shifting Boundaries: Trends in Religious and Educational Homogamy». American Sociological Review, 56, 786-800.

Kardiner, Abram (1936). The Study of Man. Nueva York: Appleton-Century-Crofts.

MERTON, Robert King (1941). "Intermarriage and the social structure: Fact and theory». Psychiatry, 4, 361-374.

- (1972). Teoría y estructuras sociales. México: Fondo de Cultura Económica.

NATION MASTER. Spanish Immigration Statistics.

[http://www.nationamaster.com/country/sp-spain/imm-immigration]

PéreZ-Díaz, Víctor; ÁlvareZ-Miranda, Berta y Chuliá, Elisa (2004). La inmigración musulmana en Europa: Turcos en Alemania, argelinos en Francia y marroquies en España. Barcelona: Fundación "la Caixa". Colección Estudios Sociales, 15. [www. estudios.lacaixa.es]

«Población extranjera en Andalucía según edad y nacionalidad. Año 1991». Anuario Estadístico de Andalucía, 1996, 2.3.9. [http://www.juntadeandalucia.es/institutodeestadistica/anuario/anuario96/cap02/02030900.htm, consulta: 21 de abril de 2009] 
RATH, Gudrun (2010). «Hybridität und Dritter Raum. Displacements postkolonialer Modelle». En: Esslinger, Eva; Schlechtriemen, Tobias; SchweItzer, Doris y Zons, Alexander (eds.). Figuren des Dritten, Frankfurt/Main: Suhrkamp, 137-149.

RitZER, George (1995). Teoría sociológica contemporánea. Madrid: McGraw-Hill.

RodríGuez Marcos, Evangelina (2006). Familias interculturales. La construcción de la interculturalidad de lo micro a lo macro. Salamanca: Universidad Pontificia de Salamanca.

SAID, Edward W. (1978). Orientalism: Western Conceptions of the Orient. Londres: Penguin.

SEgalen, Martine (2004). Antropología histórica de la familia. Madrid: Santillana [París, 1981].

STATISTIK AUSTRIA. Statistisches Bundesamt 2008. Natürliche Bevölkerungsbewegung. Eheschliessungen seit 1970 nach Staatsangehörigkeit). [http://www.statistik.at/ web_de/statistiken/bevoelkerung/eheschliessungen/index.htm]

Schroedter, Julio H. y Kalter, Frank (2008). «Binationale Ehen in Deutschland: Trends und Mechanismen der sozialen Assimilation». En: Kalter, F. (ed.). Migration und Integration, núm. especial 48 de Kölner Zeitschrift für Soziologie und Sozialpsychologie, 351-379.

SimmeL, Georg (1923). Soziologie: Untersuchungen über die Formen der Vergesellschaftung. München/Leipzig: Humboldt \& Duncker.

Sotelo, Ignacio (2006). «Disolución de la familia». El Pais, miércoles 27 de septiembre de 2006, 15.

STEINGRESS, Gerhard (2002). «La cultura como dimensión de la globalización: un nuevo reto para la sociología». Revista Española de Sociología (RES), 2, 77-96.

- (2009). "Parejas binacionales en Andalucía: datos estadísticos y reflexiones microsociológicas de hibridación transcultural en las sociedades avanzadas». En: Seminario Parejas binacionales en la sociedad avanzada..., op. cit., 126-141.

- (2011). «Couples mixtes et hybridation transculturelle en Espagne: réflexion á partir d'une recherche en cours et perspectives de comparaisons européennes». Migrations Société, XXIII (134-135), marzo-junio, 25-45.

«Tabla XIII.1». Anuario Estadístico de Extranjería 2003. [http://extranjeros.mtas.es/ es/InformacionEstadistica/Anuarios/Archivos/Anuario_de_Extranjeria_2003.pdf]

Thomas, William I. y Znaniecki, Florian (1918-1921). The Polish Peasant in Europe and America, 5 tomos. New Cork (s. e.). Versión en castellano: ZARCO, Juan (ed.) (2004). El campesino polaco en Europa y en América. Madrid: Centro de Investigaciones Sociológicas.

Verband Binationaler Familien Und Partnerschaften. Zablen und Fakten. Eheschliessungen. [www.verband-binationaler.de/zahlenundfakten], [http://www. verband-binationaler.de/seiten/file/zahlen_und_fakten.shtml]

WeLsCH, Wolfgang (1999). «Transculturality: The Puzzling Form of Cultures Today». En: Featherstone, Mike y Lash, Scott (ed.). Spaces of Culture. City, Nation, World. Londres: Sage, 194-213. 